Original Research Article

\title{
The pattern of self-medication practice among undergraduate medical students of tertiary care hospital, Andhra Pradesh, India
}

\author{
Ramya Rachamanti*, Zaheda Bano
}

Department of Pharmacology, Guntur Medical College and Hospital, Guntur, Andhra Pradesh, India

Received: 21 September 2017 Accepted: 27 October 2017

*Correspondence to: Dr. Ramya Rachamanti, Email: ramz599@gmail.com

Copyright: (C) the author(s), publisher and licensee Medip Academy. This is an openaccess article distributed under the terms of the Creative Commons Attribution NonCommercial License, which permits unrestricted noncommercial use, distribution, and reproduction in any medium, provided the original work is properly cited.

\begin{abstract}
Background: According to World Health Organization resources, Selfmedication is selection and use of drugs to treat self-diagnosed disorders or symptoms which includes the usage of non-prescription drugs. It is widely seen among undergraduate students especially in developing countries like India. Our objective of the study is to know the pattern of self-medication practice among undergraduate medicos in medical college attached to tertiary care hospital.

Methods: This is a Prospective, cross-sectional, questionnaire-based study conducted among 184 medical students of $5^{\text {th }}$ Semester in pharmacology lecture gallery, Guntur Medical College and Hospital, A.P. India. Among 200 students of 5th semester, 184 students gave the written consent for the study and submitted the given questionnaire. Fourteen questionnaires were incomplete and so the remaining 170 were analysed.

Results: Results showed that $126(74 \%)$ respondents practiced self-medication. The main health issues for seeking self-medication were found to be upper respiratory tract infection as reported by 39 students $(31 \%)$ followed by diarrhea (32 students) (25\%), fever (23 students) (18\%). Drugs commonly used were analgesics (32\%) followed by antibiotics $(24 \%)$. The reasons for practicing selfmedication were mild illness for 66 students (52\%) and time-saving for 35 students $(28 \%)$.

Conclusions: Though the self-medication practice is inevitable, drug authorities and health professionals need to educate students about the pros and cons of practicing self-medication.
\end{abstract}

Keywords: Questionnaire, Self-medication, Tertiary hospital, Undergraduate students

\section{INTRODUCTION}

"Self-medication is defined as the use of medication by any patient on his own initiative or upon the advice of a pharmacist or a layperson instead of consulting a medical practitioner". 1 Easy availability of drugs, improved quality of medicalcare, enhanced potential to manage mild illnesses through self-knowledge, increased access to health-related information lead to increased selfmedication practice. ${ }^{2,3}$ It is associated with many risks like incorrect self-diagnosis, incomplete treatment resulting in that particular disease progression and its related complications. ${ }^{4}$ Also there is delay in seeking medical advice when needed, rare but severe adverse reactions, dangerous drug-drug, drug-food interactions, incorrect manner of administration, incorrect dosage, masking of underlying disease and increased risk of drug dependence and abuse especially sedatives. ${ }^{5}$ On the other side it indicates people are taking care of their own health effectively utilizing the available resources. ${ }^{6}$ This practice is thought to reduce the load on medical services, decrease time spent to see the physician and reduce cost burden. Appropriate self-medication practice requires an individual to correctly recognize all the symptoms pertaining to disease and to set the therapeutic objectives. To determine the appropriate dosage and dosage schedule, we have to take into account the personal history, medical 
history, contraindications and possible adverse effects of various drugs. Information from friends/relatives, media, internet is unreliable. More attention should be given to consumers as the ultimate users of drugs so that they can assess the credibility of information and ask necessary questions. As per Indian law, self-medication is allowed for (over the counter) O.T.C drugs only but there is no specific list of O.T.C drugs in India. ${ }^{7}$

The aim of present study was to know the prevalence and pattern of self-medication practice among medical undergraduate students in Andhra Pradesh. Many studies were previously done in different countries. Their prevalence and pattern were found to vary. ${ }^{8-12}$ All the studies proved that the increased knowledge is the leading cause for increased self-medication practice.

\section{METHODS}

This study was a cross-sectional, questionnaire-based study conducted among undergraduate medical students in the pharmacology lecture gallery of Guntur Medical College \& Hospital, Guntur, A.P. India.

\section{Inclusion criteria}

200 Undergraduate Medical students of Guntur Medical College, Guntur who belong to $5^{\text {th }}$ semester who were studying pharmacology having some idea about drugs or medications were only involved.

\section{Exclusion criteria}

House surgeons, post graduates who already passed M.B.B.S (Bachelor of medicine and Bachelor of surgery) final examination were excluded as they have the eligibility to prescribe medication to others or for their own purpose. $1^{\text {st }}$ and $2^{\text {nd }}$ semester undergraduate students who just joined the medical college who have no knowledge about any kind of medication or self-medication were excluded.

Students were informed about the purpose of study, time spent and confidentiality details. Among 200 students of $5^{\text {th }}$ semester, 184 students gave the written consent for the study. A Questionnaire form containing 10 questions was given to each student. They were told to fill up the form and return the form after completion. They can ask doubts if any. Questionnaire form was framed in such a way to know the complete pattern of how frequently students take medicines, reasons and which medicines they use on their own without consulting the physician. Their knowledge and attitude towards self-medication was also tested. In the questionnaire form, out of 10 questions, 2 questions were based on 5 point likert scale. This scale was followed as it increases the credibility of the data.one question was related to their gender identity to know the differences in prevalence of self-medication practice among males and females. One question was a definitive one with options yes or no which tests their knowledge about over the counter and prescription only drugs and if they choose "yes" they have to mention them in a single sentence to avoid unnecessary biased opting of option 'yes'. 6 were multiple choice questions. Among them 5 questions are testing the pattern and their attitude about self-medication practice and 1 question is testing their source of knowledge for self-medication practice. The question about the morbidities or illnesses for which they practice selfmedication was framed such that the mentioned illnesses were more common in the society. Options for medications they use is such that those medications were easily available over the counter in pharmacy. System of medicine question was related to know if students were also taking alternate medicines like Homeopathy, Ayurveda and Siddha on their own without specialist prescription on which they have very less or no knowledge. Frequency of self-medication practice question was framed to know if they were doing that in the past or even now also. The question that they were prescribing medicines to non-medical people was asked to know how irrationally they prescribe the medicines with no complete knowledge.

Students have to select one single best option in multiple choice questions. Students who didn't practice any kind of self-medication can opt for "not applicable" option for questions asking the reasons for self-medication, frequency of self-medication, which medicines they use, for which morbidity or illness they use or source of information about the medicine they use or which system of medicine they follow. 14 incomplete questionnaire forms were removed and remaining 170 questionnaire forms were evaluated graphically through Microsoft word excel sheet of windows 10. Results were also expressed in percentage.

\section{RESULTS}

It was found that 126 students $(74 \%)$ respondents agreed they practice self-medication.44 students disagree or didn't use any kind of medicines on their own without physician consultation.

\section{Table 1: Likert Point scale showing number of students practicing self medication.}

\begin{tabular}{|ll|}
\hline You practice self-medication & No. of students \\
\hline Strongly agree & 78 \\
\hline Agree & 48 \\
\hline Un decided & 0 \\
\hline Disagree & 20 \\
\hline Strongly dis agree & 22 \\
\hline
\end{tabular}

Among 126 students who practice self-medication, 78 were females and 48 were males.

39 students attributed the main morbidity for seeking selfmedication is upper respiratory tract infections, 32 students attributed to diarrhea, 23 students mentioned 
fever, 21 students mentioned headache and 11 students mentioned pain in abdomen as morbidities.

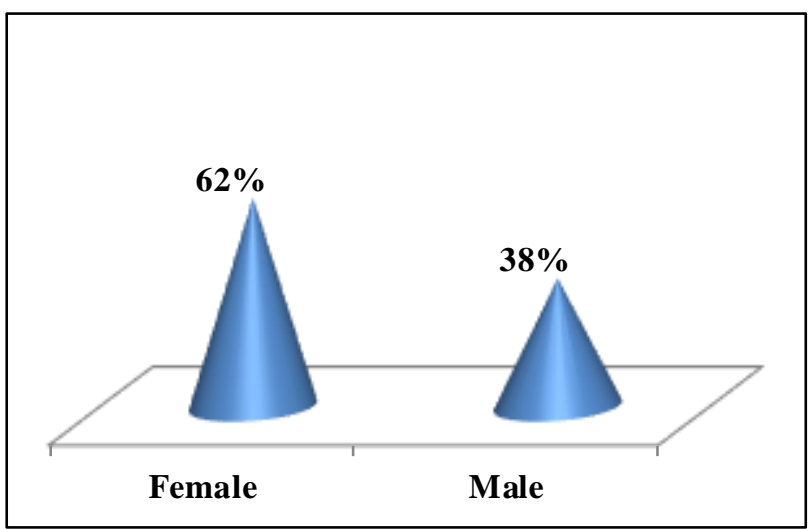

Figure 1: Gender wise prevalence of self-medication practice among undergraduate students expressed in \%.

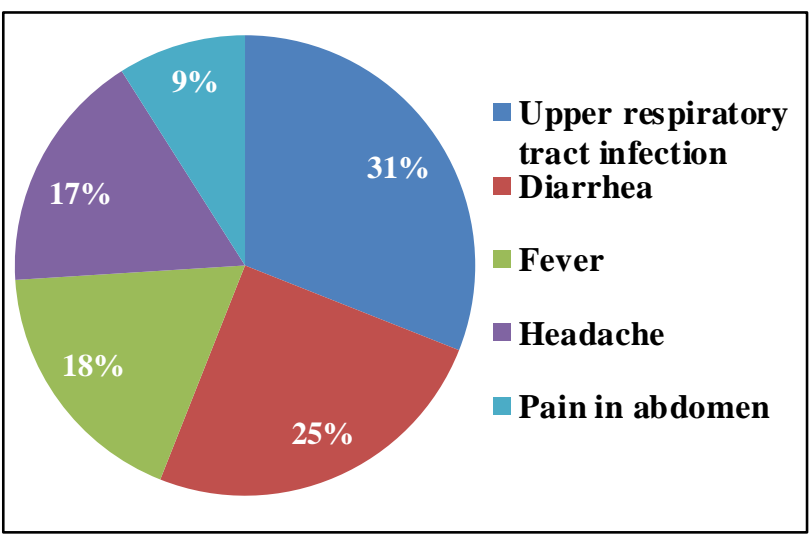

Figure 2: Percentage of students using self-medication for common morbidities/illness.

40 students used analgesics/painkillers, 30 students used antibiotics, 23 students used antipyretics like paracetamol, 10 students used antacids or anti- ulcer agents, 9 students used cough suppressants, 8 students used multivitamins and 6 students used anti-helminthic drugs.

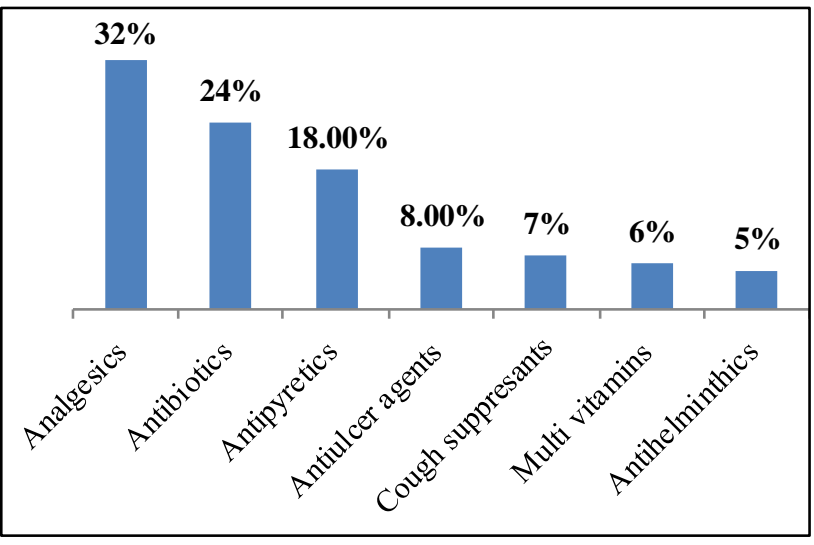

Figure 3: Percentage of group or class of drugs used as self medication.
59 students felt that their illness is mild,35 students felt it as time- saving, 20 students felt it as money saving, 8 students felt urgency and 4 students had past similar experience and taken prescription from the physician.

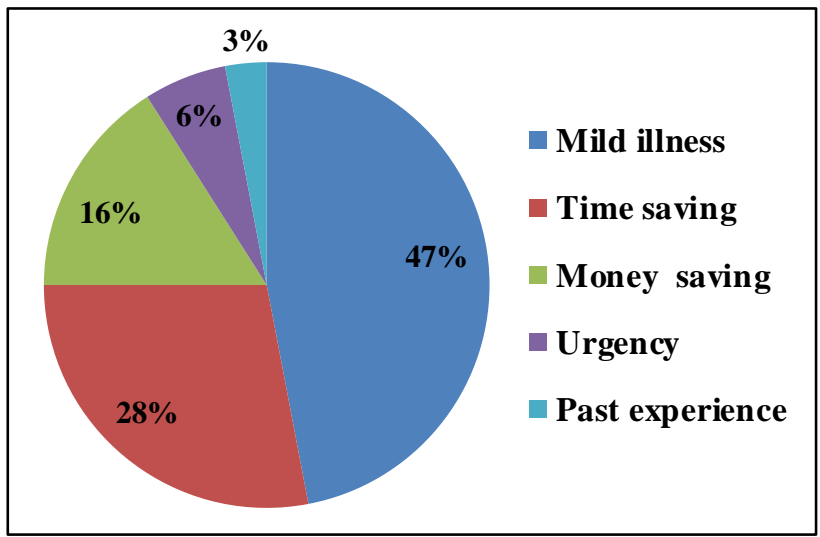

Figure 4: Various reasons for self medication practice among medical students.

The source of knowledge regarding the drugs they were using: 63 students mentioned the source is from their medical books, 48students mentioned Internet, media and magazines, 15 students mentioned there are physicians in their own family.

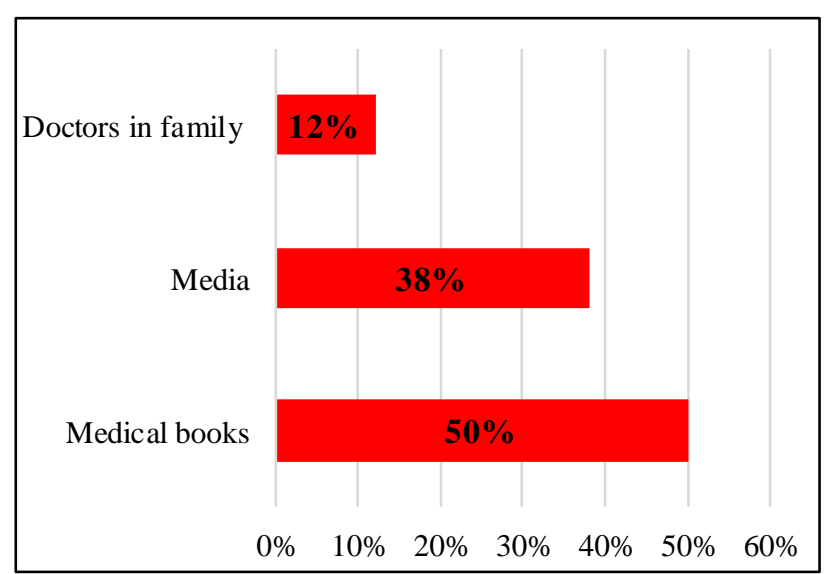

Figure 5: Source of knowledge regarding the medication they use.

Results proved that majority of students are taking medicines on their own 1- times a month.

It was found that 90 students out of 170 were prescribing medicines on their own to their friends, family members also. Among them 22 students don't use self-medication but still prescribing to their friends and family members and 154 students out of 170 had no awareness about over the counter and prescription-only drugs.

Results shown that all $126(100 \%)$ students use only allopathy system of medicine for self-medication which indicates though students take alternate medicines like 
homeopathy, they take only after consulting specialist person.

Table 2: Frequency of self-medication practice among medical students.

\begin{tabular}{|ll|}
\hline Frequency & No of students \\
\hline $1-5$ times/year & 40 \\
\hline $1-5$ times/month & 70 \\
\hline $6-10$ times/month & 14 \\
\hline More than 10 times/month & 2 \\
\hline
\end{tabular}

Table 3: No of students having awareness about O.T.C and P.O drugs.

\begin{tabular}{|lll|}
\hline $\begin{array}{l}\text { Awareness about Over the } \\
\text { counter (O.T.C) drugs }\end{array}$ & Yes & No \\
\hline No of students & 16 & 154 \\
\hline
\end{tabular}

\section{DISCUSSION}

Most of the students are practicing self-medication which indicates high incidence among medicos. There is a difference in gender among that practicing selfmedication. Females were more may be due to their menstrual and hormonal problems. Mostly they are using medicines for simple ailments like cold, fever etc. which are non-serious. The high use of analgesics for selfmedication confirms the findings that analgesics are the commonly used over-the-counter medicines. ${ }^{13}$ These results were consistent with the study "Popularity of selfmedication among medical students AIIMS" by Gupta $\mathrm{YK}^{14}$ Multivitamins were also used commonly as supplements for promoting health, for preventing the illness, for boosting the immune system, for prevention of stress and to top up the regular nutrition. ${ }^{15}$ Self-medication with antibiotics is of public health concern because inappropriate use of antibiotics results in antibiotic resistance and in emergence of mutant forms of microbes which is a major problem worldwide especially in developing countries like India. ${ }^{16}$

The limitations in this study was the study population may not be representative, and it was based on the information obtained from the students which are prone to recall error and bias in reporting.

Although this practice is inevitable, drug authorities and health care professionals need to educate the students about the pros and cons of self-medication practice. ${ }^{17}$ Rational use of medicines must be encouraged through proper and complete consultation from professional medical specialist only.

\section{ACKNOWLEDGEMENTS}

Authors would like to thank to the Principal of Guntur Medical College \& Hospital and the participated students for spending their valuable time.
Funding: No funding sources Conflict of interest: None declared

Ethical approval: The study was approved by the Institutional Ethics Committee

\section{REFERENCES}

1. WHO guidelines for the regulatory assessment of medical products for use in self-medication. 2000. [Last accessed on 2012]. Available at: http://www.who.int/medicine/library/qs m/whoedmqsm-2000-1/who-ed m-qsm-00_1.htm

2. Verma RK, Mohan L, Pandey M. Evaluation of selfmedication among professional students in North India: Proper statutory drug control must be implemented. Asian J Pharm Clin Res. 2010;3:60-4.

3. WHO Consultive Group. Report of the $4^{\text {th }}$. The Role of the Pharmacist in Self-care and Self-medication. 1998. Available at: http://apps.who.int/medicinedocs/en/d/Jwhozip32e/

4. Awad AI, Eltayeb IB. Self-medication practices with antibiotics and antimalarials among Sudanese undergraduate university students. Ann Pharmacother. 2007;41:1249-55.

5. Hughes CM, McElnay JC, Fleming GF. Benefits and risks of self-medication. Drug Safety. 2001;24(14):1027-37.

6. Khantzian EJ. The Self-Medication Hypothesis of Substance Use Disorders. A Reconsideration and Recent Applications. 1997;4(5):231-44.

7. Jaina P, Sachanb A, Singlac RK. Agrawal P. Statistical Study on Self Medication Pattern in Haryana, India. Indo Global Journal of Pharmaceutical Sciences. 2012;2(1):21-35.

8. Zafar SN, Syed R, Waqar S, Zubairi AJ, Vaqar T, Shaikh M. Self-medication amongst University Students of Karachi, Prevalence, Knowledge and Attitudes. J Pak Med Assn. 2008;58:214-7.

9. Klemenc-Ketis Z, Hladnik Z, Kersnik J. Selfmedication among healthcare and non-healthcare students at University of Ljubljana, Slovenia. Med Princ Pract. 2010;19:395-401.

10. Sontakke SD, Bajait CS, Pimpalkhute SA, Jaiswal KM, Jaiswal SR. Comparative study of evaluation of self-medication practices in first and third year medical students. Int J Biol Med Res. 2011;2:561-4.

11. James H, Handu SS, Al Khaja KA, Otoom S, Sequeria RP. Evaluation of the knowledge, attitude, and practice of self-medication among first-year medical students. Med Princ Pract. 2006;15:270-5.

12. Abay SM, Amelo W. Assessment of self-medication practices among medical, pharmacy, and health science students in Gondhar University, Ethiopia. J Young Pharm. 2010;2:306-10.

13. Fox JM. Use of analgesics in self-medication. Therapie. 2002 Mar-Apr;57(2):115-8.

14. Gupta YK. Self-medication popular among medical students, AIIMS. Available at: http://www.livemint.com/Politics/XcN44QD5g8aW4 
dwltcUdtI/Selfmedication-popular-among-med icalstudents-AIIMS-study.html

15. Haenen GR, Bast A. The use of vitamin supplements in self-medication. Therapie. 2002 MarApr;57(2):119-22.

16. Grigoryan L, Monnet DL, Haaijer-Ruskamp FM, Bonten MJ, Lundborg S. Self-medication with antibiotics in Europe. a case for action: Curr Drug Saf. 2010 Oct;5(4):329-32.
17. Silva IM, Catrib AM, de Matos VC, Gondim AP. Selfmedication in adolescence: a challenge to health education. Cien Saude Colet. 2011;16(1):1651-60.

Cite this article as: Rachamanti $\mathrm{R}$, Bano $\mathrm{Z}$. The pattern of self-medication practice among undergraduate medical students of tertiary care hospital, Andhra Pradesh, India. Int J Basic Clin Pharmacol 2017;6:2848-52. 